\title{
Benign Neonatal Sleep Myoclonus in Uyo: Presentations, Diagnosis and Outcome
}

\author{
Eno Etim Nyong, MBBS, FWACP*, Mkpouto Udeme Akpan, MBBS, FWACP, Paulinus \\ Umoren Essien, MBBS, FWACP and Itoro Anietimfon Akpan, MBBS, FWACP \\ Department of Paediatrics, University of Uyo Teaching Hospital, Nigeria
}

\begin{abstract}
Background: Myoclonic jerks are rhythmic movement of the limbs which occur when a baby is drowsy or asleep. It is infrequently reported and under-recognized.

Objective: To highlight the occurrence of myoclonus which are occasionally misdiagnosed when proper and adequate history is not taken.

Method and subjects: To describe four neonates with jerky movements of the limbs who were seen in University of Uyo Teaching Hospital between January 2014 to December 2018. They were all referred from other facilities for further management. The characteristics of the jerky movements were profiled and other confounding clinical states were excluded.
\end{abstract}

Result: There were sudden involuntary jerks of one or more extremities which occurred during sleep, commencing in the first week of life and which resolved by itself with no neurologic sequalae. It was commonly misdiagnosed here.

Conclusion: Benign sleep myoclonus is not uncommon in this environment. A high index of suspicion should be entertained.

\section{Keywords}

Benign, Myoclonus, Rhythmic, Movement, Sleep

\section{Abbreviations}

Csf: Cerebrospinal Fluid; MBBS: Bachelors of Medicine and Surgery; FWCAP: Fellow of the West African College of Physicians; MCS: Microscopy culture and sensitivity; RBS: Random blood sugar; UUTH: University of Uyo Teaching Hospital

\section{Introduction}

Jerky, sudden, brief involuntary movement of the limbs is described as myoclonus [1]. They are repetitive and rhythmic. Benign neonatal sleep myoclonus is when these jerky movement occurs during sleep but stop during awakening and is associated with normal encephalography [2,3]. This condition was first described by Culter and Allen [4]. The jerks are more commonly located in the distal part of the extremities but occasionally may involve the face [5] or abdomen [6]. Myoclonic limb movement may transit from one limb to another [7]. Sometimes they are misdiagnosed [8]. Most last less than 5 minutes but some may last up 15-30 minutes and disappear spontaneously or from provoked arousal [8-10]. Occasionally there can be bouts that occur in series [11]. Age of onset of this condition is in the first few days to second week of life but few can occur for the first time between 15 and 35 days of life $[5,12,13]$. Familial occurrences were documented in some by Vaccario, et al. [14], Cohen, et al. [15], Kaddurah and Holmes [6].

\section{Case 1: Baby UN}

Age at presentation was 5 hours, birth weight was $3.9 \mathrm{~kg}$, APGAR score 9 [1] 10 [5] and a male sex. The presenting complaints were twitching of all limbs of 4 hours duration; this involved the upper and lower limbs at different occasions but mainly involved the upper limbs and lasted 2-3 seconds. It occurred during sleep and aborted spontaneously. There was no fever and no risk factors for sepsis. The baby was given ampiclox drops and glucose water before presentation. The

*Corresponding author: Eno Etim Nyong, MBBS, FWACP, Department of Paediatrics, University of Uyo Teaching Hospital, Uyo, Akwa Ibom State, Nigeria, Tel: +2348182220326

Accepted: March 16, 2021

Published online: March 18, 2021

Citation: Nyong EE, Akpan MU, Essien PU, et al. (2021) Benign Neonatal Sleep Myoclonus in Uyo: Presentations, Diagnosis and Outcome. J Pediatr Neurol Neurosci 5(1):95-98 
temperature was normal throughout admission. Antenatal care was in a private hospital and the delivery was by elective caesarian section on account of post date. He is the first child in a monogamous family. The father is a 30 -years professional with tertiary level of education and the mother, a 29-years old housewife with a secondary level of education. There is no family history of seizures.

Examination revealed normal neurological findings. Investigation that included electrolyte and urea, full blood count and lumbar puncture were essentially normal except for mild acidosis which was corrected. Serum calcium was $2.3 \mathrm{mmol} / \mathrm{L}$ and Random blood sugar was $3.1 \mathrm{mmol} / \mathrm{L}$. The initial considerations were Benign neonatal clonus to rule out i) Transient homeostatic problems; ii) Neonatal meningitis. He was discharged after receiving 4 days of antibiotic when investigations did not establish any causative factor. Follow up was excellent.

\section{Case 2: Baby AGE}

Weight on admission was 3.15, APGAR score: Said to have cried at birth. A male sex. Age at presentation was 11 days. The presenting complaints were jerky movements of upper and lower limbs for 7 days and lasted on the average of 1 minute. It occurred during sleep and aborted spontaneously. There was no fever and no risk factors for sepsis except for the place of delivery which was the traditional birth attendant's place. The baby was given ampiclox suspension, abidex and citramin (Vitamin C) before presentation.

The mother had Antenatal Care in the University of Uyo Teaching Hospital (UUTH) Uyo. The pregnancy was uneventful. The mode of delivery was by spontaneous vaginal delivery at term. The baby is the third child in a monogamous family of 3. The father is a 35-years-old man who runs a block-making company and the mother is a 33-year-old seamstress with secondary level of education. There is no family history of seizures.

Examination revealed normal neurological findings. Investigations that included electrolyte and urea, full blood count and lumbar puncture were essentially normal. Serum calcium was $2.5 \mathrm{mmol} / \mathrm{L}$ and Random blood sugar was $5.4 \mathrm{mmol} / \mathrm{L}$.

The initial consideration was benign neonatal myoclonus to rule out neonatal meningitis. Intravenous phenobarbitone was initially given but discontinued after 3 days. The patient also received intravenous antibiotics which were discontinued after seven days when available results turned in were normal. The mother was counselled and discharged despite a few more jerks. Follow up revealed that the baby had a few more jerky movements at home but no neurological deficit. All seizures abated after 12 days of having been discharged and further follow up was good.

\section{Case 3: Baby UEI}

Age at presentation was 3 days, weight on admission 3.8 $\mathrm{kg}$, APGAR SCORE was 7 [1] 8 [5], a male sex. The presenting complaints were abnormal movements of the limbs for 6 hours. This involved all the limbs though at different times and lasted on the average of 3-5 minutes. It occurred during sleep and aborted spontaneously. There were no risk factors for sepsis. The baby was given ampiclox suspension and Phenergan (promethazine) in a private Health facility before referral. Temperature was normal throughout admission except for one isolatory spike. The mother had Antenatal care in a private Health facility. The pregnancy was uneventful. The delivery was by emergency Caesarian section.

The patient is the third child of a monogamous family. The father is 49-year-old clergy with tertiary level of education and the mother is a civil servant with tertiary level of education.

\section{Examination revealed normal neurologic findings.}

Investigation that included electrolyte and urea, full blood count were essentially normal. Cerebrospinal fluid (csf) analysis revealed slight decrease in CSF sugar/RBS ratio. Protein was normal and microscopy, culture and sensitivity (mcs) yielded no growth. Malaria parasite was not seen. Serum calcium $2.2 \mathrm{mmol} / \mathrm{L}$.

The initial consideration was Benign neonatal myoclonus to rule out meningitis. The patient had intravenous antibiotics for twenty-one days on account of the slightly reduced csf sugar/RBS ratio and the persistence of jerky movements, the isolatory spike, as a precautionary measure against leaving a partially treated meningitis. The patient was subsequently discharged. Patient still had occasional jerky movements but disappeared at the age of 7 weeks. There was no neurological deficit or other complication on follow up.

\section{Case 4: Baby VTP}

Age at presentation was 3 weeks. Weight on Admission was $3.1 \mathrm{~kg}$. APGAR SCORE was 7 [1] 9 [5], a female sex. The presenting complaints were jerky movements of the limbs for two weeks, fever of one day duration. The jerky movements affected the upper and lower limbs and lasted two minutes. They occurred during sleep and aborted spontaneously or on awakening. Fever was low grade. There were no risk factors for sepsis. The mother gave the baby paracetamol, gripe water and Nospamin for "abdominal pain". The temperature was normal throughout admission.

The mother had Antenatal care in a private health facility. The pregnancy was uneventful and she had spontaneous vaginal delivery.

She is the first child of the family. The father is a 30-yearold secondary school teacher with a tertiary level of education. The mother is 21-year-old unmarried, unemployed secondary school leaver. The father supported the treatment and upkeep financially. The father was said to have had a similar problem as a newborn.

\section{Examination revealed normal neurologic findings.}

Investigation including electrolyte and urea, full blood count and csf analysis were essentially normal. Malaria parasite was not seen.

Initial earlier consideration was benign neonatal myoclonus to rule out associated malaria. She was discharged after three days of antibiotics when the result obtained were 
essentially normal. The follow up did not reveal any jerks or seizures.

\section{Discussion}

Four cases of benign neonatal myoclonus were documented over a 5-years period (2014-2018), giving an incidence rate of 1.23 per 1,000 admissions. This is similar to two previous reports in which the incidence varied from 0.8-3 per $1000[10,16]$. This buttresses the fact that it is uncommon and most likely misdiagnosed as there were other considerations at initial evaluation. The diagnosis of neonatal sleep myoclonus was made according to the following parameters: Neonatal onset, jerky movement occurring during sleep and cessation on arousal. Three of the babies (75\%) were males and three of them (75\%) were healthy term neonates and one was post-date and was in keeping with findings of a review of literature [17]. It has however been shown that it can affect near term neonates and infants with mild muscular hypotonia or hyper excitability $[13,15]$. The general conditions of the infants were completely unaffected except for one that had low grade fever that subsided almost immediately after admission. The mean weight was $3.49 \mathrm{~kg}$. The age of onset ranged from one hour to seven days with the mean age of onset being three days. In majority of cases reviewed, the age of onset was one to fourteen days [17] with the maximal expression of myoclonus ranging from thirteen to thirty- five days in very few cases $[5,12,13]$.

Pregnancy and delivery history for the mothers were essentially uneventful except for the first case in which the only perinatal alarm indicator was the Caesarian section on account of post-datism. Low APGAR was not documented in any of the cases.

All the jerks occurred during sleep, with most of them involving all the limbs and all stopped on arousal or on waking. This is consistent with the scenario found in other studies $[1,2,4,6]$. There were occasional jerks involving only one limb at a time as has been shown in some studies $[6,18]$. In two of the cases, the jerky movements occurred in series and were repetitive for some prolonged period. There were no documented facial or abdominal jerks. Initiation and synchronization of normal sleep pattern is thought to occur when there are discharges from the reticular activation system. The benign sleep myoclonus appears to occur as a result of interference with the brainstem control of sleep.

The haemato-chemistry and lumbar puncture findings were essentially normal in all of them except for the mild acidosis in one instance and slightly reduced cerebrospinal fluid sugar level in relation to the blood sugar level in another instance. This necessitated prolonged antibiotic administration to forestall partially treated meningitis outcome as the jerks had persisted longer than in others.

Electroencephalography was not done for any of the neonate because it was not available in our facility at the period and so differentiation of any of the jerks from epileptiform jerks was not done. The diagnosis of benign neonatal sleep has been suspected on clinical grounds in most of the cases. Lack of sufficient awareness among the physicians who first evaluated all the cases led to unnecessary testing and commencement of antibiotic and phenobarbitone in one instance. These were discontinued immediately the diagnosis was established.

Familial occurrence was said to have occurred in the father of one of the Cases (Case 4). The jerks in all cases disappeared under two months of life. In a review by Maurer, et al. [17], $64 \%$ of infants with benign neonatal myoclonus had resolved by three months or less while $95 \%$ of cases had resolved by less than 6 months and $97 \%$ by less than 12 months. The follow up of our cases, though for a short period (under five years) has been excellent with no neurologic deficit, though Kaddurah and Holmes [6], Paro-Panjan and Neubauer [13] had noted neurologic deficit during their follow up.

\section{Authors Contribution}

Eno Nyong: Conception, design and drafting of manuscript; Mkpouto Akpan: Reviewed of the $1^{\text {st }}$ manuscript draft; Paulinus Essien: Design and review of manuscript; Itoro Akpan: Drafting and review of the manuscript.

All the authors read and approved the final drafting.

\section{Ethical Considerations}

Ethical approval was sought from the institutional Health research committee of the University of Uyo Teaching Hospital.

\section{Source of Funding}

No source of funding.

\section{Conflict of Interest}

The authors declare no conflict of interest.

\section{References}

1. Caviness JN, Brown P (2004) Myoclonus: Current Concepts and recent advances. Lancet Neurol 3: 598-607.

2. Armentrout DC, Cante I (2001) The jittery newborn. J Pediat Health Care 15: 147-149.

3. Montagna P (2004) Sleep-related non-epileptic motor disorders. J Neurol 251: 781-794.

4. Culter DI, Alvin I (1982) Benign neonatal sleep myoclonus. Arch Neurol 39: 191-192.

5. Yepezi CR, Cersosimo, Feierman N (1998) Bening neonatal sleep myoclonus (in Spanish). Arch Agent Pediatr 96: 12-17.

6. Kaddurah AK, Holmes GI (2009) Benign neonatal sleep myoclonus history and seminology. Pediatr Neurology 40: 343-346.

7. Besnick TI, Moshé SI, Perottai, et al. (1986) Benign neonatal sleep myoclonus relationship to sleep states. Arch Neurol 43: 266-268.

8. Daoust-Roy J, Seshia SS (1992) Benign neonatal sleep myoclonus. A differential diagnosis of neonatal seizures. Am J Dis Child 146: $1236-1241$.

9. Blennow G (1985) Benign infantile nocturnal myoclonus. ActaPediatr Scand 74: 505-507.

10. Fager I, Grossman G, Auchterlonie IA (2003) Benign sleep myoclonus in infancy mistaken for epilepsy. BMJ 326: 975-976. 
Citation: Nyong EE, Akpan MU, Essien PU, et al. (2021) Benign Neonatal Sleep Myoclonus in Uyo: Presentations, Diagnosis and Outcome. J Pediatr Neurol Neurosci 5(1):95-98

11. Turanli G, Senbil N, Altunbacksak S, et al. (2004) Benign neonatal sleep myoclonus mimicking epilepticus. J Child neurol 19: 62-33.

12. John BM, Patnaik SK (2006) Benign neonatal sleep myoclonus: Is it common? Med J Armed forces India 62: 186-187.

13. Paro-Panjan DE, Neubaeur D (2008) Benign neonatal sleep myoclonus experience from the study of 38 infants. Env J Padiatr Neurol 12: 14-18.

14. Vaccario ML, Valenti MA, Carullo A, et al. (2003) Benign neonatal sleep myoclonus: Case report and follow-up of four members of an effected family. Clin Electroencephalography 34: 15-17.
15. Cohen R, Shuper A, Strausberg R (2007) Familial benign neonatal sleep myoclonus. Pediatr Neurol 36: 334-337.

16. Ramelli GP, Sozzo AB, Vella S, et al. (2005) Benign neonatal sleep myoclonus: An under-recognized, non-epileptic condition. Acta Paediatr 94: 962-963.

17. Maurer VO, Rizz M, Bianchetti MG (2010) Benign neonatal sleep myoclonus: A review of literature. Pediatrics 125: 919-924.

18. Noone PG, Kirg M, Loftus BG (1995) Benign neonatal sleep myoclonus. Benign neonatal sleep myoclonus. Ir Med J 88: 172. 